\title{
SIKAP MAHASISWA TERHADAP FASILITAS DAN PELAYANAN PERPUSTAKAAN UNIVERSITAS ATMA JAYA YOGYAKARTA
}

\author{
Ignatia Mardyantiwi *) \\ ABSTRACT \\ Student's Attitude toward the Facilities and Services \\ of Atma Jaya Yogyakarta University Library
}

The objectives of the study on attitude are: (1) to investigate the attitude of the students toward the facilities and the services of Atma Jaya Yogyakarta University library and (2) to uncover the difference in the attitude of the students majoring in exact disciplines and those majoring in non-exact ones toward the facilities and the services of the Atma Jaya Yogyakarta University library. The study is conducted in the Atma Jaya Yogyakarta University with 200 samples as respondents. They consist of 100 degree students majoring in exact disciplines and 100 degree students majoring in nonexact disciplines. The analysis of the study is quantitative-descriptively conducted and the method employed is of applied statistics one. Subsequently, the analysis and the hypothesis are examined using one-way ANOVA.The result of the study shows that: (1) the attitude of the students toward the facilities of the Atma Jaya Yogyakarta University library tends to be both positive and negative in general. There are $4.5 \%$ of the 200 respondents having negative attitude, $41.5 \%$ having the tendency of negative attitude, $49.5 \%$ having the tendency of positive attitude; and (2) the attitude of the students toward the service of the Atma Jaya yogyakarta University library tends to be positive in general. There are $2 \%$ of the 200 respondents having negative attitude, $18 \%$ having the tendency of negative attitude, $60 \%$ having the tendency of positive attitude, $19.5 \%$ having positive attitude and $0.5 \%$ having very positive attitude; (3) there is a significant difference in attitude between the students majoring in exact disciplines and those majoring in non-exact disciplines toward the facilities and the services of the Atma Jaya Yogyakarta University library. The student majoring in non-exact disciplines have more positive attitude than those majoring in exact disciplines; and (4) there is a significant difference in the attitude between the students majoring in exact disciplines and those majoring in non-exact disciplines. The difference in attitude is found especially in the services of information tracing and copying. The attitude of the students majoring in exact disciplines is more positives than those majoring in non-exact disciplines toward the two services.

Keywords: Student attitude ; Library Facilities ; Library Services

*) Chief Librarian, Atma Jaya University Yogyakarta

\section{ABSTRAK}

Objek dari penelitian ini adalah sikap para mahasiswa terhadap fasilitas dan pelayanan dari perpustakaan Universitas Atma Jaya Yogyakarta dan perbedaan sikap mahasiswa bidang studi eksakta dan non eksakta terhadap fasilitas dan pelayanan perpustakaan. Penelitian ini melibatkan 200 responden yang terdiri dari 100 mahasiswa eksakta dan 100 non eksakta. Analisis penelitian menggunakan kuantitatif deskriptif dengan penerapan metode statistik. Untuk menguji hipotesis nol digunakan analisis varians sederhana atau analisis satu jalur (one way anova) Hasil penelitian membuktikan bahwa: 1). Sikap para mahasiswa terhadap fasilitas dari perpustakaan Universitas Atma Jaya Yogyakarta secara umum cenderung positif dan negatif. 4,5\% dari 200 responden mempunyai sikap negatif, 41,5\% mempunyai kecenderungan sikap negatif, 49,5\% sikapnya positif. 2). Sikap dari mahasiswa terhadap pelayanan di perpustakaan Universitas Atma Jaya Yogyakarta secara umum ada kecenderungan positif. $2 \%$ dari 200 responden mempunyai sikap negatif, $18 \%$ cenderung sikapnya negatif, $60 \%$ sikapnya cenderung positif, dan 0,5\% sangat positif, 19,5\% sikapnya positif. 3) Ada perbedaan yang signifikan antara mahasiswa eksakta dan non eksakta terhadap fasilitas dan pelayanan perpustakaan. 4) Ada perbedaan sikap antara mahasiswa khususnya dari pelayanan informasi dan fotokopi. Sikap mahasiswa eksakta lebih positif dibandingkan dengan mahasiswa non eksakta terhadap pelayanan di Perpustakaan Universitas Atma Jaya Yogyakarta.

Kata Kunci: Sikap Mahasiswa ; Fasilitas Perpustakaan ; Pelayanan Perpustakaan

*) Kepala Perpustakaan Universitas Atma Jaya Yogyakarta 


\section{PENDAHULUAN}

Undang-undang Nomor 2 Tahun 1989 tentang Sistem Pendidikan Nasional menyebutkan bahwa perguruan tinggi yang mengemban misi pendidikan lanjutan bertujuan menyiapkan peserta didik menjadi anggota masyarakat yang memiliki kemampuan akademik dan / atau profesional yang dapat menerapkan, mengembangkan dan / atau menciptakan ilmu pengetahuan, teknologi dan / atau kesenian.

Supaya misi pendidikan dapat berhasil dengan baik, maka suatu perguruan tinggi harus dilengkapi dengan sarana penunjang yang mampu menyediakan informasi yang sesuai dengan kebutuhan sivitas akademika. Sarana penunjang tersebut adalah perpustakaan yang merupakan pusat informasi dimana bahan pustaka dikumpulkan, diolah, dan disebarluaskan agar dimanfaatkan semaksimal mungkin oleh penggunanya.

Banyak ahli pendidikan menyatakan bahwa mutu suatu lembaga pendidikan (perguruan tinggi khususnya) dapat dilihat dari perpustakaannya (Haryanto, 1988 : 29). Pernyataan tersebut memang bukan tanpa alasan sebab kualitas pendidikan dan riset di lembaga perguruan tinggi sangat dipengaruhi oleh kualitas perpustakaannya.

Perpustakaan dinyatakan baik jika perpustakaan memiliki persyaratan antara lain adalah : (1) koleksi relevan, aktual dan akurat, (2) SDM yang profesional, (3) sistem layanan yang cepat dan (4) didukung oleh sarana prasarana yang memadai. Selanjutnya perpustakaan dinyatakan berhasil jika pengguna jasa perpustakaan merasa puas karena kebutuhannya terpenuhi.

Memasuki abad 21 atau lebih dikenal dengan abad informasi terjadi pergeseran paradigma layanan dalam dunia perpustäkaan, dokumentasi, dan informasi yakni bergesernya layanan yang berorientasi pada sistem layanan yang berorientasi pada pemakai. Perubahan dan pergeseran ini diantisipasi oleh perpustakaan Universitas Atma Jaya Yogyakarta dengan menetapkan visi, misi dan tujuan yang lebih jelas.

Tujuan perpustakaan Universitas Atma Jaya Yogyakarta adalah memberikan kepuasan kepada pengguna melalui koleksi yang relevan, aktual dan akurat, SDM yang profesional, sistem layanan yang cepat dan tepat dan didukung oleh sarana prasarana yang memadai

Perpustakaan Universitas Atma Jaya Yogyakarta telah melaksanakan berbagai program pengembangan yaitu : pengembangan SDM, pengembangan koleksi, pengembangan layanan dan pengembangan sarana prasarana. Hasil yang dapat dicatat setelah program pengembangan tersebut di atas dilakukan yaitu meningkatnya : SDM yang profesional, jumlah koleksi, jumlah peminjaman dan pengunjung serta fasilitas perpustakaan. Meskipun terdapat perkembangan yang cukup berarti namun perpustakaan Universitas Atma Jaya Yogyakarta masih memiliki berbagai kekurangan. Hal ini ditunjukkan dengan adanya beberapa masukan terutama dari mahasiswa antara lain tentang koleksi perpustakaan yang kurang memadai baik dari segi kualitas maupun kuantitas.

Bertolak dari pemikiran-pemikiran tersebut di atas, penulis ingin mengetahui keberhasilan perpustakaan Universitas Atma Jaya Yogyakarta dalam melaksanakan visi, misi dan tujuannya. Untuk mengetahui tingkat keberhasilannya salah satu cara yang dilakukan adalah dengan melihat sikap mahasiswa. Penulis mengambil pengertian sikap yang dikemukakan oleh Thurstone yaitu sebagi tingkatan aspek yang bersifat positif maupun negatif dalam hubungannya dengan obyek lainnya (Walgito, 1983 : 51). Dari latar belakang itulah penulis berminat melakukan penelitian tentang bagaimana sikap mahasiswa terhadap fasilitas dan pelayanan perpustakaan Universitas Atma Jaya Yogyakarta.

Berdasarakan uraian seperti yang telah tertulis di dalam latar belakang tersebut di atas, maka tujuan penulisan ini 
adalah:

1. Untuk mengetahui sikap mahasiswa terhadap fasilitas dan pelayanan perpustakaan Universitas Atma Jaya Yogyakarta. Dengan mengetahui sikap mahasiswa akan diperoleh gambaran kemungkinan yang akan timbul sebagai respon atau tindakan mahasiswa terhadap fasilitas dan pelayanan perpustakaan. Hal ini akan sangat bermanfaat bagi perpustakaan Universitas Atma Jaya Yogyakarta dalam menyusun strategi dan kebijakan pengembangan selanjutnya.

2. Untuk mengetahui perbedaan sikap antara mahasiswa bidang studi eksakta dan mahasiswa bidang studi noneksakta terhadap fasilitas dan pelayanan perpustakaan Universitas Atma Jaya Yogyakarta.

\section{CARA PENELITIAN}

Penelitian dilakukan di perpustakaan Universitas Atma Jaya Yogyakarta dengan mengambil lokasi di perpustakaan kampus I, perpustakaan kampus II dan perpustakaan kampus III. Sebagai responden adalah 200 mahasiswa Universitas Atma Jaya Yogyakarta program strata satu (S.1) yang terdaftar pada tahun akademi 1999 / 2000 yang terdiri dari 100 mahasiswa bidang studi eksakta (teknik, teknologi industri dan biologi) dan 100 mahasiswa bidang studi noneksakta (ekonomi, hukum dan ilmu sosial dan politik). Metode pengumpulan data yang penulis gunakan dalam penelitian ini adalah studi kepustakaan dan kuesioner. Penyebaran kuesioner dilakukan pada saat mahasiswa memasuki perpustakaan dan jawaban kuesioner diserahkan pada saat mahasiswa keluar dari ruangan perpustakaan.

Jenis kuesioner dalam penelitian ini adalah kuesioner tertutup dan kuesioner dengan skala Likert. Kuesioner tertutup adalah kuesioner yang sudah disediakan jawabannya sehingga responden tinggal memilih pada kolom yang sudah disediakan dengan memberikan tanda centang (v) (Arikunto, 1998 : 151). Kuesioner dengan skala Likert adalah instrument yang umum digunakan untuk meminta responden, agar memberikan respon terhadap beberapa statemen dengan menunjukkan apakah dia sangat setuju, setuju, tidak menentukan, tidak setuju, sangat tidak setuju terhadap tiaptiap statemen (Sumanto, 1995 : 66). Jawabab-jawaban ini diberi skor 1 sampai 5 .

Analisa yang digunakan penulis dalam penelitian ini adalah analisa kuantitatif deskriptif dengan penerapan metode statistik. Untuk mengetahui sikap mahasiswa terhadap fasilitas dan pelayanan perustakaan Universitas Atma Jaya Yogyakarta yang terangkum dalam hipotesa, digunakan Metode Rating yang dijumlahkan (Method of Summated Ratings) yaitu metode penskalaan pernyataan sikap yang menggunakan distribusi respons sebagai dasar penentuan relasi skalanya.

Hipotesis yang diangkat dalam penelitian ini adalah hipotesis nol yang berarti tidak ada perbedaan sikap antara mahasiswa bidang studi eksakta dan bidang studi noneksakta. Untuk menguji hipotesis nol digunakan analisis varians sederhana atau analisis varians satu jalur (one way anova). Anova ini digunakan untuk menentukan apakah ada perbedaan yang signifikan antara dua mean atau lebih pada suatu tingkat probabilitas tertentu yang dipilih.

\section{HASIL PENELITIAN DAN PEMBAHASAN}

\section{A. Sikap Mahasiswa Terhadap Fasilitas Perpustakaan} Universitas Atma Jaya Yogyakarta

Berdasarkan pada hasil pemrosesan dan pengolahan data dapat diketahui sikap mahasiswa terhadap fasilitas perpustakaan Universitas Atma Jaya Yogyakarta sebagai berikut :

1. Nilai rerata pada sikap mahasiswa adalah 42,30 dengan variat tertinggi 56,00 dan variat terendah 
27,00. karena nilai rerata sebesar 42,30 ditafsirkan cenderung positif dan cenderung negatif, maka hipotesis kerja sikap mahasiswa terhadap fasilitas perpustakaan Universitas Atma Jaya Yogyakarta adalah positif, tidak dapat diterima.

2. Sebaran sampel dalam prosentase skor sikap mahasiswa menunjukkan : 9 mahasiswa atau 41,5\% bersikap negatif, 83 mahasiswa bersikap cenderung negatif, 99 mahasiswa atau 49,5\% bersikap cenderung positif dan 9 mahasiswa atau 4,5\% bersikap positif.

3. Berdasarkan nilai rerata butir skala sikap mahasiswa terhadap fasilitas perpustakaan Universitas Atma Jaya Yogyakarta, dapat disimpulkan sebagai berikut

a. Sikap mahasiswa terhadap luas gedung dan ruangan adalah positif, dengan nilai rerata 3,805 . Sikap positif artinya sikap senang yang ditunjukkan oleh mahasiswa karena perpustakaan dapat menyediakan gedung atau ruangan yang luasnya dianggap memadai untuk memenuhi kebutuhan mahasiswa.

b. Sikap mahasiswa terhadap letak perpustakaan adalah cenderung negatif, dengan nilai rerata 2,630. sikap cenderung negatif adalah sikap kurang senang yang ditunjukkan oleh mahasiswa terhadap letak perpustakaan.

c. Sikap mahasiswa terhadap perabot perpustakaan adalah positif, dengan nilai rerata 3,735. Sikap positif adalah sikap senang yang ditunjukkan oleh mahasiswa terhadap perabot yang ada di perpustakaan.

d. Sikap mahasiswa terhadap perlengkapan perpustakaan adalah negatif, dengan nilai rerata 2,020. Sikap negatif adalah sikap tidak senang yang ditunjukkan oleh mahasiswa terhadap perlengkapan yang dimiliki oleh perpustakaan.

e. Sikap mahasiswa terhadap kenyamanan perpustakaan adalah positif, dengan nilai rerata 3,880. Sikap positif adalah sikap senang yang ditunjukkan mahasiswa terhadap kenyamanan perpustakaan.

f. Sikap mahasiswa terhadap sirkulasi udara adalah cenderung positif, dengan nilai rerata 3,545. Sikap cenderung positif adalah sikap cukup senang yang ditunjukkan oleh mahasiswa terhadap sirkulasi udara yang ada di ruangan perpustakaan.

g. Sikap mahasiswa terhadap koleksi buku wajib adalah negatif, dengan nilai rerata 2,985. Sikap negatif adalah sikap tidak senang yang ditunjukkan oleh mahasiswa terhadap koleksi buku wajib yang dimiliki perpustakaan.

h. Sikap mahasiswa terhadap koleksi buku penunjang adalah negatif, dengan nilai rerata 1,750. Sikap negatif adalah sikap tidak senang yang ditunjukkan oleh mahasiswa terhadap koleksi buku penunjang yang dimiliki perpustakaan.

i. Sikap mahasiswa terhadap koleksi referensi adalah negatif, dengan nilai rerata 1,975 . Sikap negatif adalah sikap tidak senang yang ditunjukkan oleh mahasiswa terhadap koleksi referensi yang dimiliki perpustakaan.

j. Sikap mahasiswa terhadap koleksi skripsi adalah cenderung negatif, dengan nilai rerata 2,985 . Sikap cenderung negatif adalah sikap kurang senang yang ditunjukkan oleh mahasiswa terhadap koleksi skripsi yang ada di perpustakaan.

k. Sikap mahasiswa terhadap koleksi majalah adalah cenderung positif, dengan nilai rerata 
3,610. Sikap cenderung positif adalah sikap cukup senang yang ditunjukkan oleh mahasiswa terhadap koleksi majalah yang dilanggan perpustakaan.

1. Sikap mahasiswa terhadap kemutakhiran koleksi adalah positif, dengan nilai rerata 3,805 . Sikap positif adalah senang yang ditunjukkan oleh mahasiswa terhadap koleksi mutakhir yang disediakan perpustakaan.

m. Sikap mahasiswa terhadap koleksi surat kabar adalah cenderung positif, dengan nilai rerata 3,585. Sikap cenderung positif adalah sikap cukup senang yang ditunjukkan oleh mahasiswa terhadap koleksi surat kabar yang dilanggan perpustakaan.

n. Sikap mahasiswa terhadap koleksi audio visual

- adalah negatif, dengan nilai rerata 1,930. Sikap negatif adalah sikap tidak senang yang ditunjukkan mahasiswa terhadap koleksi audio visual yang ada di perpustakaan.

Dari kesimpulan tersebut di atas dapat dikemukakan bahwa Perpustakaan Universitas Atma Jaya Yogyakarta harus melakukan pembenahan, pengembangan, dan peningkatan di bidang fasilitas perpustakaan terutama, (1) letak perpustakaan, (2) perlengkapan perpustakaan dan (3) koleksi: wajib, penunjang, referensi, skripsi dan audio visual.

\section{(1) Letak Perpustakaan}

Letak perpustakaan Universitas Atma Jaya Yogyakarta terutama di kampus I dan kampus III tidak berada di tengahtengah kampus bahkan letaknya terkesan tersembunyi. Kondisi ini tidak sesuai dengan yang dikemukakan oleh Thompson (1973:28) dan Daryanto (1985:29) tentang lokasi perpustakaan yang intinya sebagai berikut: "Perpustakaan merupakan salah satu pusat kegiatan belajar mengajar, maka secara fisik lokasi perpustakaan hendaknya mudah dicapai dari berbagai pusat kegiatan yang lain." Mengubah letak perpustakaan yang kurang strategis menjadi strategis bukan pekerjaan yang mudah dilakukan sebab memerlukan dana dan lokasi yang cukup luas, oleh karena itu salah satu upaya yang harus dilakukan oleh perpustakaan Universitas Atma Jaya Yogyakarta adalah menciptakan perpustakaan menjadi tempat yang menarik yang selalu diminati dan dikunjungi oleh pengguna.

\section{(2) Perlengkapan Perpustakaan}

Sikap mahasiswa terhadap perlengkapan perpustakaan adalah negatif menunjukkan bahwa perpustakaan Universitas Atma Jaya Yogyakarta belum mampu menyediakan perlengkapan yang memadai untuk memenuhi kebutuhan pengguna. Jenis perlengkapan perpustakaan yang saat ini perlu ditambah jumlahnya adalah : komputer, CD-ROM drive dan mesin fotokopi.

\section{(3) Koleksi Perpustakaan}

Sikap mahasiswa terhadap koleksi perpustakaan adalah cenderung negatif menunjukkan bahwa pengembangan koleksi perpustakaan Universitas Atma Jaya Yogyakarta belum berjalan baik terutama untuk koleksi : wajib, penunjang, referensi, skripsi dan audio visual. Hal ini tidak sejalan dengan harapan para pakar seperti Chirgwin (1988), Gorman (1991) dan Magrill (1989) bahwa koleksi hendaknya sesuai dengan kebutuhan pemakai dan mudah diakses (Asrukin, 1994 : 53).

Agar mahasiswa bersikap positif terhadap ketersediaan koleksi maka upaya perpustakaan Universitas Atma Jaya Yogyakarta adalah : (a) melakukan pembinaan dan pengembangan koleksi secara berkesinambungan, (b) melakukan perbaikan dan pengembangan sistem dan prosedur pengedaan koleksi dan (c) mengatasi hambatan internal maupun eksternal yang dialami oleh perpustakaan Universitas Atma Jaya Yogyakarta di dalam melakukan pengembangan koleksi.

B. Sikap Mahasiswa Terhadap Pelayanan Perpustakaan

Berdasarkan hasil pemrosesan data dan pengolahan 
angket dapat diketahui sikap mahasiswa terhadap pelayanan perpustakaan sebagai berikut :

1. Sikap mahasiswa terhadap pelayanan perpustảkaan memiliki nilai rerata sebesar 46,590 dengan variat tertinggi sebesar 63 dan variat terendah sebesar 24. Nilai rerata 46,590 adalah masuk dalam kategori cenderung positif sehingga hipotesa kerja yang dinyatakan penulis yakni sikap mahasiswa terhadap pelayanan perpustakaan Universitas Atma Jaya Yogyakarta adalah positif, tidak dapat diterima.

2. Sebaran sampel dalam prosentase skor sikap mahasiswa terhadap pelayanan perpustakaan Universitas Atma Jaya Yogyakarta menunjukkan 4 mahasiswa atau $2 \%$ bersikap negatif, 36 mahasiswa atau $18 \%$ bersikap cenderung negatif, 120 mahasiswa atau $60 \%$ bersikap cenderung positif, 39 mahasiswa atau $19,5 \%$ bersikap positif dan 1 orang atau $0,5 \%$ bersikap sangat positif.

3. Nilai rerata butir skala sikap mahasiswa terhadap pelayanan perpustakaan Universitas Atma Jaya Yogyakarta menurut bagian-bagiannya dapat disimpulkan sebagai berikut :

a. Sikap mahasiswa terhadap prosedur dan peraturan perpustakaan adalah positif dengan nilai rerata 3,835 . Sikap positif adalah sikap senang yang ditunjukkan oleh mahasiswa terhadap prosedur dan peraturan perpustakaan Universitas Atma Jaya Yogyakarta.

b. Sikap mahasiswa terhadap waktu pelayanan adalah cenderung negatif dengan nilai rerata 2,505. Sikap cenderung negatif adalah sikap kurang senang yang ditunjukkan oleh mahasiswa terhadap waktu pelayanan yang ditentukan oleh perpustakaan Universitas Atma Jaya Yogyakarta.

c. Sikap mahasiswa terhadap sistem pelayanan adalah positif dengan nilai rerata 3,745. Sikap positif adalah sikap senang yang ditunjukkan oleh mahasiswa terhadap sistem pelayanan yang diterapkan perpustakaan Universitas Atma Jaya Yogyakarta.

d. Sikap mahasiswa terhadap pelayanan sirkulasi adalah positif dengan nilai rerata 3,780. Sikap positif adalah sikap senang yang ditunjukkan oleh mahasiswa terhadap pelayanan sirkulasi perpustakaan Universitas Atma Jaya Yogyakarta.

e. Sikap mahasiswa terhadap pelayanan referensi adalah cenderung positif dengan nilai rerata 3,430. Sikap cenderung positif adalah sikap cukup senang yang ditunjukkan oleh mahasiswa terhadap pelayanan referensi.

f. Sikap mahasiswa terhadap pelayanan majalah adalah cenderung positif dengan nilai rerata 3,375. Sikap cenderung positif adalah sikap cukup senang yang ditunjukkan oleh mahasiswa terhadap pelayanan majalah.

g. Sikap mahasiswa terhadap pelayanan skripsi adalah cenderung positif dengan nilai rerata 3,351. Sikap cenderung positif adalah sikap cukup senang yang ditunjukkan oleh mahasiswa terhadap pelayanan skripsi.

h. Sikap mahasiswa terhadap pelayanan surat kabar adalah cenderung positif dengan nilai rerata 3,075 . Sikap cenderung positif adalah sikap cukup senang yang ditunjukkan oleh mahasiswa terhadap pelayanan surat kabar.

i. Sikap mahasiswa terhadap pelayanan penelusuran informasi adalah cenderung positif dan cenderung negatif dengan nilai rerata 3,005. Sikap cenderung positif adalah sikap cukup senang yang ditunjukkan oleh mahasiswa 
terhadap pelayanan penelusuran informasi sedangkan sikap cenderung negatif adalah sikap kurang senang yang ditunjukkan oleh mahasiswa terhadap pelayanan penelusuran informasi.

j. Sikap mahasiswa terhadap pelayanan bimbingan adalah cenderung positif dengan nilai rerata 3,205. Sikap cenderung positif adalah sikap senang yang ditunjukkan oleh mahasiswa terhadap pelayanan bimbingan yang diselenggarakan perpustakaan Universitas Atma Jaya Yogyakarta.

k. Sikap mahasiswa terhadap pelayanan fotokopi adalah cenderung positif dan cenderung negatif dengan nilai rerata 3,060 . Sikap cenderung positif adalah sikap cukup senang yang

- ditunjukkan oleh mahasiswa terhadap pelayanan fotokopi dan sikap cenderung negatif adalah sikap kurang senang yang ditunjukkan oleh mahasiswa terhadap pelayanan fotokopi.

1. Sikap mahasiswa terhadap ketrampilan petugas adalah cenderung positif dengan nilai rerata 3,255. Sikap cenderung positif adalah sikap cukup senang yang ditunjukkan oleh mahasiswa terhadap ketrampilan petugas.

m. Sikap mahasiswa terhadap keramahan petugas adalah cenderung positif dengan nilai rerata 3,650. Sikap cenderung positif adalah sikap cukup senang yang ditunjukkan oleh mahasiswa terhadap petugas perpustakaan yang bersikap ramah.

n. Sikap mahasiswa terhadap penampilan petugas adalah cenderung positif dengan nilai rerata 3,535. Sikap cenderung positif adalah sikap cukup senang yang ditunjukkan oleh mahasiswa terhadap petugas perpustakaan yang berpenampilan cukup baik.

Berdasarkan pada hasil pengolahan dan kesimpulan yang dikemukakan di atas maka dapat dinyatakan bahwa secara umum pelayanan perpustakaan Universitas Atma Jaya Yogyakarta adalah cukup baik, namun demikian jasa layanan yang masih harus ditingkatkan terutama mengenai waktu pelayanan, pelayanan penelusuran dan pelayanan fotokopi.

C. Perbedaan Sikap Antara Mahasiswa Bidang Studi Eksakta dan Mahasiswa Bidang Studi Noneksakta Terhadap Fasilitas Perpustakaan Universitas Atma Jaya Yogyakarta

Menjawab permasalahan kedua yakni apakah ada perbedaan sikap antara mahasiswa bidang studi eksakta dan bidang studi noneksakta terhadap fasilitas perpustakaan Universitas Atma Jaya Yogyakarta, dilakukan analisis uji Anova 1 jalur (oneway Anova). Dari hasil pengolahan dapat diketahui :

1. $\mathrm{F}_{\text {hitung }}=0,541$. Jika dibandingkan dengan $F_{\text {tabel }}=5,23$, maka $\mathrm{F}_{\text {hitung }}<\mathrm{F}_{\text {tabel }}$. Hal ini menunjukkan ada perbedaan sikap antara mahasiswa bidang studi eksakta dan noneksakta terhadap fasilitas perpustakaan Universitas Atma Jaya Yogyakarta, dengan nilai probabilitas 0,525 yang lebih besar dari á $=0,05$, jadi tidak signifikan karena nilai probabilitas lebih besar dari á = 0,05 maka hipotesis nol yang dinyatakan penulis bahwa tidak ada perbedaan sikap antara mahasiswa bidang studi eksakta dan noneksakta terhadap fasilitas perpustakaan, tidak dapat diterima.

2. Secara umum perbedaan sikap kedua kelompok bidang studi tersebut tidak menunjukkan perbedaan yang berarti atau perbedaan yang menonjol. Perbedaan sikap terutama terletak pada koleksi wajib dan koleksi skripsi. Terhadap kedua jenis koleksi 
tersebut, sikap mahasiswa bidang studi noneksakta lebih positif jika dibandingkan dengan sikap mahasiwa bidang studi eksakta.

D. Perbedaan Sikap Antara Mahasiswa Bidang Studi Eksakta dan Bidang Studi Noneksakta Terhadap Pelayanan Perpustakaan Universitas Atma Jaya Yogyakarta.

Menjawab permasalahan kedua, apakah ada perbedaan sikap antara mahasiswa bidang studi eksakta dan mahasiswa bidang studi noneksakta terhadap pelayanan perpustakaan Universitas Atma Jaya Yogyakarta, dilakukan analisis uji Anova 1 jalur (one way Anova). Dari hasil pengolahan dapat diketahui :

1. $\mathrm{F}_{\text {hitung }}=0,579$. Jika dibandingkan dengan $\mathrm{F}_{\text {tabel }}=4,23$, maka $F_{\text {hitung }}<\mathrm{F}_{\text {tabel. }}$ Hal ini menunjukkan ada perbedaan sikap antara mahasiswa bidang studi eksakta dan noneksakta terhadap pelayanan perpustakaan Universitas Atma Jaya Yogyakarta, dengan nilai probabilitas 0,540 yang lebih besar dari á $=0,05$. jadi tidak signifikan. Dengan demikian hipotesis nol yang dinyatakan penulis bahwa tidak ada perbedaan sikap antara mahasiswa bidang studi eksakta dan bidang studi noneksakta terhadap pelayanan perpustakaan, tidak dapat diterima.

2. Secara umum sikap antara mahasiswa bidang studi eksakta dan noneksakta terhadap pelayanan tidak menunjukkan perbedaan yang berarti. Perbedaan sikap antara dua kelompok bidang studi terletak pada pelayanan penelusuran informasi dan pelayanan fotokopi. Terhadap kedua macam pelayanan tersebut, sikap mahasiswa bidang studi eksakta lebih positif jika dibandingkan dengan sikap mahasiswa bidang studi noneksakta.

\section{KESIMPULAN}

Berdasarkan pada pembahasan hasil penelitian tentang sikap mahasiswa terhadap fasilitas dan pelayanan perpustakaan Universitas Atma Jaya Yogyakarta diperoleh kesimpulan sebagai berikut :

Pertama, perpustakaan Universitas Atma Jaya Yogyakarta belum optimal di dalam menyediakan fasilitas perpustakaan yang dibutuhkan oleh mahasiswa. Fasilitas perpustakaan tersebut terutama adalah gedung perpustakaan yang strategis, perlengkapan perpustakaan dan koleksi : wajib, penunjang, referensi, skripsi dan audio visual.

Kedua, perpustakaan Universitas Atma Jaya yogyakarta dalam memberikan layanan kepada mahasiswa cukup baik namun ada beberapa bagian pelayanan yang harus diperbaiki, dikembangkan dan ditingkatkan terutama adalah waktu pelayanan, pelayanan penelusuran dan pelayanan fotokopi.

Ketiga ,terdapat perbedaan sikap antara mahasiswa bidang studi eksakta dan mahasiswa bidang studi noneksakta terhadap fasilitas perpustakaan Universitas Atma Jaya Yogyakarta. Perbedaan sikap terutama terletak pada koleksi wajib dan koleksi skripsi. Terhadap kedua jenis koleksi, sikap mahasiswa bidang studi noneksakta lebih positif jika dibandingkan dengan sikap mahasiswa bidang studi eksakta.

Keempat, terdapat perbedaan sikap antara mahasiswa bidang studi eksakta dan mahasiswa bidang noneksakta terhadap pelayanan perpustakaan Universitas Atma Jaya Yogyakarta. Perbedaan sikap terutama terletak pada pelayanan penelusuran informasi dan pelayanan fotokopi. Terhadap kedua macam pelayanan tersebut, sikap mahasiswa bidang studi eksakta lebih positif jika dibandingkan dengan sikap mahasiswa bidang studi noneksakta. 


\section{DAFTAR PUSTAKA}

Arikunto, Suharsimi, 1995. Manajemen penelitian, Jakarta, Departemen Pendidikan dan Kebudayaan.

Asrukin, Mochamad, 1994. Sikap mahasiswa terhadap fasilitas dan pelayanan perpustakaan IKIP Malang. Tesis, UI, Jakarta.

Daryanto, 1985. Pengetahuan praktis bagi pustakawan. Bandung : Bina Cipta.

Haryanto, Sugeng, 1998. Pemanfaatan perpustakaan oleh mahasiswa Universitas Merdeka Malang, Jurnal penelitian I (I) Maret: $28-42$.

Line, Maurice B (ed), 1990. Academic library management, London: The Library Associated.

Thompson, Godfrrey, 1974. Planning and design of library buildings, New York: Von Nostrand Reinhold.

Walgito, Bimo, 1983. Psikologi sosial: suatu pengantar, Yogyakarta: Fakultas Psikologi UGM. 